\title{
Sasanquasaponin promotes cellular chloride efflux and elicits cardioprotection via the PKCE pathway
}

\author{
LING-YU QIU, HE-PING CHEN, YU-FENG YAN, YUAN-YUAN LI, \\ HUAN WANG, ZHANG-PING LIAO and QI-REN HUANG
}

\begin{abstract}
The Key Laboratory of Basic Pharmacology, School of Pharmaceutical Science, Nanchang University, Nanchang, Jiangxi 330006, P.R. China
\end{abstract}

Received March 17, 2015; Accepted February 6, 2016

DOI: $10.3892 / \mathrm{mmr} .2016 .4984$

\begin{abstract}
Sasanquasaponin (SQS) is an active component of Camellia oleifera Abel. A recent study by our group demonstrated that SQS was able to inhibit ischemia/reperfusion-induced elevation of the intracellular chloride ion concentration $\left(\left[\mathrm{Cl}^{-}\right]_{\mathrm{i}}\right)$ and exerted cardioprotective effects; however, the underlying intracellular signal transduction mechanisms have yet to be elucidated. As protein kinase $\mathrm{C} \varepsilon$ (PKC $\varepsilon$ ) is able to mediate $\mathrm{Cl}^{-}$homeostasis, the present study investigated its possible involvement in the effects of SQS on cardiomyocytes subjected to ischemia/reperfusion injury. Cardiomyocytes were pre-treated with or without SQS or SQS plus $\varepsilon V 1-2$, a selective PKCE inhibitor, followed by simulated ischemia/reperfusion (sI/R). The effects on cell viability, PKC $\varepsilon$ phosphorylation levels, $\left[\mathrm{Cl}^{-}\right]_{\mathrm{i}}$, mitochondrial membrane potential and reactive oxygen species (ROS) production were assessed using an MTS assay, western blot analysis, colorimetric assays and flow cytometry. The results revealed that treatment with SQS prior to $\mathrm{SI} / \mathrm{R}$ increased the viability of cardiomyocytes, and efficiently attenuated lactate dehydrogenase and creatine phosphokinase release induced by $\mathrm{SI} / \mathrm{R}$. In addition, SQS promoted PKCE phosphorylation and inhibited sI/R-induced elevation of $\left[\mathrm{Cl}^{-}\right]_{i}$, paralleled by the attenuation of mitochondrial membrane potential loss and ROS generation. However, when the cardiomyocytes were treated with $\varepsilon V 1-2$ prior to SQS pre-conditioning, the cardioprotection induced by SQS was reduced and the inhibitory effects of SQS on sI/R-induced elevation of $\left[\mathrm{Cl}^{-}\right]_{\mathrm{i}}$, production of ROS and loss of mitochondrial membrane potential were also attenuated. These findings indicated that SQS may inhibit sI/R-induced elevation of $\left[\mathrm{Cl}^{-}\right]_{\mathrm{i}}$ through the $\mathrm{PKC} \varepsilon$ signaling pathway to elicit cardioprotection in cultured cardiomyocytes.
\end{abstract}

Correspondence to: Professor He-Ping Chen, The Key Laboratory of Basic Pharmacology, School of Pharmaceutical Science, Nanchang University, 461 Ba-Yi Road, Nanchang, Jiangxi 330006, P.R. China

E-mail: chenheping69@hotmail.com

Key words: sasanquasaponin, cardioprotection, protein kinase Ce signaling pathway, chloride

\section{Introduction}

Myocardial ischemia/reperfusion (I/R) injury is the most common cause of cardiac morbidity and mortality and can lead to arrhythmia, heart hypofunction, cardiocyte apoptosis and other disorders (1). Therefore, identification of therapeutic approaches and molecular mechanisms responsible for I/R injury are important for the improvement of ischemic heart diseases associated with $\mathrm{I} / \mathrm{R}$.

It has been suggested that elevation of the intracellular chloride ion concentration $\left(\left[\mathrm{Cl}_{\mathrm{i}}^{-}\right]_{\mathrm{i}}\right)$ is an important pathophysiological factor of I/R injury. Increased $\left[\mathrm{Cl}^{-}\right]_{i}$ can activate $\mathrm{Cl}^{-}-\mathrm{OH}^{-}$exchange activity $(2,3)$, thereby increasing the intracellular concentration of $\mathrm{OH}^{-}$, which is an important member of the reactive oxygen species (ROS) family. Alternatively, the increased $\left[\mathrm{Cl}^{-}\right]_{\mathrm{i}}$ may induce the opening of the mitochondrial permeability transition pore (mPTP), which results in a ROS burst and subsequent ROS-dependent apoptosis $(4,5)$. Therefore, the inhibition of the elevation of $\left[\mathrm{Cl}^{-}\right]_{\mathrm{i}}$ induced by $\mathrm{I} / \mathrm{R}$ has been considered to be a reasonable therapeutic strategy to alleviate I/R injury.

Sasanquasaponin (SQS) is an active component of Camellia oleifera Abel, which is used in Traditional Chinese Medicine. SQS is a triterpenoid with structural similarity to certain ginseng saponins $(6,7)$, and is known to exert potent cardioprotective effects against I/R injury (8). A previous study by our group indicated that these beneficial effects of SQS may be attributed to the inhibition of I/R-induced elevation of $\left[\mathrm{Cl}^{-}\right]_{i}(9)$; however, the intracellular signal transduction mechanisms underlying these effects have yet to be elucidated.

Protein kinase $\mathrm{C}$ epsilon (PKCE), a novel PKC isotype characterized as a calcium-independent and phorbol ester/diacylglycerol-sensitive serine/threonine kinase $(10,11)$, has been well documented to have an important role in cardioprotection (12-15). Several recent studies have reported that PKC $\varepsilon$ signaling is involved in maintaining intracellular chloride homeostasis $(2,16)$.

Considering that PKCe signaling has important roles in the regulation of $\left[\mathrm{Cl}^{-}\right]_{\mathrm{i}}$ and in cardioprotection, and that SQS can effectively inhibit I/R-induced elevation of $\left[\mathrm{Cl}^{-}\right]_{\mathrm{i}}$, the present study hypothesized that the cardioprotective effects of SQS against I/R injury are mediated by PKC $\varepsilon$ via attenuation of $\left[\mathrm{Cl}^{-}\right]_{i}$ increases following I/R. To verify this hypothesis neonatal rat cardiomyocytes were subjected to simulated (s) 
$\mathrm{I} / \mathrm{R}$ as an in vitro $\mathrm{I} / \mathrm{R}$ model, and the effects of $\mathrm{SQS}$ on cell viability, $\mathrm{PKC} \varepsilon$ phosphorylation levels, $\left[\mathrm{Cl}^{-}\right]_{\mathrm{i}}$, mitochondrial membrane potential $(\Delta \psi \mathrm{m})$ and ROS production were assessed.

\section{Materials and methods}

Reagents. SQS was kindly provided by Professor Yongming Luo from Jiangxi Chinese Medical University (Nanchang, China), and its identity and purity (>99\%) were determined by nuclear magnetic resonance spectroscopy and high-performance liquid chromatography tandem mass spectroscopy analyses. $\varepsilon V 1-2$, a specific inhibitor of PKCE, was purchased from Anaspec (cat. no. AS-62186; Fremont, CA, USA) Anti-PKC $\varepsilon$ and anti-phosphorylated (p)-PKC $\varepsilon$ (Ser 729) antibodies were purchased from Santa Cruz Biotechnology, Inc. (Dallas, TX, USA). Anti- $\beta$-actin antibody was purchased from the Jiancheng Bioengineering Institute of Nanjing (Nanjing, China). The horseradish peroxidase-labeled immunoglobulin G secondary antibody was purchased from Cell Signaling Technology, Inc. (Danvers, MA, USA).

Cell culture. Cardiomyocytes from 30 Sprague-Dawley rats (weight, 10-15 g; age, 1-3 days; Nanchang University School of Medicine, Nanchang, China) were prepared according to the protocol of a previous study (17). The rats were treated in accordance with the National Institute of Health's Guide for the Care and Use of Laboratory Animals, and all procedures were approved by the ethics committee of Nanchang University (Nanchang, China). The rats were anesthetized by intraperitoneal injection with $10 \%$ chloral hydrate $(0.03 \mathrm{ml} / \mathrm{kg}$; Sigma-Aldrich, St. Louis, MO, USA), after which they were sacrificed by cervical dislocation prior to the removal of the rat hearts. The hearts were removed and placed in phosphate-buffered saline (PBS). The ventricles were digested with $0.1 \%$ trypsin (Beijing Solarbio Science \& Technology Co., Ltd., Beijing, China) and then collected by centrifugation at $60 \mathrm{x}$ g for $10 \mathrm{~min}$, re-suspended in plating medium, including $85 \%$ Eagle's minimum essential medium, $15 \%$ fetal calf serum and $100 \mathrm{U} / \mathrm{ml}$ penicillin and streptomycin (Beijing Solarbio Science \& Technology Co., Ltd.), seeded in a culture dish and incubated for $2 \mathrm{~h}$ in an atmosphere containing $95 \%$ air and $5 \% \mathrm{CO}_{2}$ to remove non-myocytes. The supernatant was collected and plated in $60-\mathrm{mm}$ gelatin-coated culture dishes at $1 \times 10^{6}$ cells per dish. After $24 \mathrm{~h}$, cardiomyocytes were washed and the medium was replaced, followed by incubation for three days prior to the experiments.

Experimental groups and treatments. The neonatal primary rat cardiomyocytes were divided into various experimental groups as follows: i) In the control group, cardiomyocytes were incubated under normal conditions for an additional $24 \mathrm{~h}$; ii) in the sI/R group, cardiomyocytes were subjected to anoxia by incubating them in fresh anoxic medium $[0.9 \mathrm{mM}$ $\mathrm{NaH}_{2} \mathrm{PO}_{4}, 6.0 \mathrm{mM} \mathrm{NaHCO}{ }_{3}, 1.8 \mathrm{mM} \mathrm{CaCl}_{2}, 1.2 \mathrm{mM} \mathrm{MgSO}_{4}$, $40 \mathrm{mM}$ sodium lactate, $20 \mathrm{mM}$ 4-(2-hydroxyethyl)-1-piperazineethanesulfonic acid (HEPES), $98.5 \mathrm{mM} \mathrm{NaCl}, 10.0 \mathrm{mM}$ $\mathrm{KCl}, \mathrm{pH}$ 6.8; Sigma-Aldrich] at $37^{\circ} \mathrm{C}$ in a chamber containing $95 \% \mathrm{~N}_{2}$ and $5 \% \mathrm{CO}_{2}$ for $3 \mathrm{~h}$. Subsequently, the medium was replaced with re-oxygenation medium $(129.5 \mathrm{mM} \mathrm{NaCl}$, $5.0 \mathrm{mM} \mathrm{KCl}, 0.9 \mathrm{mM} \mathrm{NaH} \mathrm{PO}_{4}, 20 \mathrm{mM} \mathrm{NaHCO}{ }_{3}, 1.8 \mathrm{mM}$ $\mathrm{CaCl}_{2}, 1.2 \mathrm{mM} \mathrm{MgSO}$, $5.5 \mathrm{mM}$ glucose, $20 \mathrm{mM}$ HEPES,
$\mathrm{pH}$ 7.4; Sigma-Aldrich) and the cells were incubated at $37^{\circ} \mathrm{C}$ in an atmosphere of $95 \%$ air and $5 \% \mathrm{CO}_{2}$ for $2 \mathrm{~h}$; iii) In the $\mathrm{SQS}+\mathrm{sI} / \mathrm{R}$ group, cells were pre-treated with SQS at $10 \mu \mathrm{M}$ for $24 \mathrm{~h}$ prior to $\mathrm{sI} / \mathrm{R}$; iv) In the $\mathrm{SQS}+\varepsilon V 1-2+\mathrm{sI} / \mathrm{R}$ group, cells were pre-treated with $\varepsilon V 1-2(1 \mu \mathrm{M})$ and SQS $(10 \mu \mathrm{M})$ for $24 \mathrm{~h}$ prior to sI/R. The doses of SQS and $\varepsilon V 1-2$ used were selected on the basis of a preliminary study by our group and previous reports $(8,18,19)$.

Cell viability assay. A colorimetric MTS assay was used to assess the viability of cardiomyocytes subjected to sI/R. MTS is a pale yellow substrate that is converted into a dark blue formazan product by living cells. Primary cardiomyocytes were seeded into 96-well plates at $1 \times 10^{4}$ cells/well. After sI/R treatment, cells were incubated with $20 \mu \mathrm{l}$ MTS $(5 \mathrm{mg} / \mathrm{ml}$; Promega Corp., Madison, WI, USA) in $100 \mu 1$ medium at $37^{\circ} \mathrm{C}$ for $2 \mathrm{~h}$. The absorbance of each well at a wavelength of $490 \mathrm{~nm}$ was then measured using a microplate reader (no. 680; Bio-Rad Laboratories, Inc., Hercules, CA, USA). The results were expressed as a percentage of the control.

Biochemical parameters. Following sI/R treatment, the culture media of the control groups and the supernatants of cell lysates from each group were collected to the activities of creatine phosphokinase (CPK) and lactate dehydrogenase (LDH) were assessed using kits (A020-2 and A032, respectively; Jiancheng Bioengineering Institute of Nanjing), according to the manufacturer's instructions.

Measurement of intracellular ROS. ROS levels were determined using the fluorescent probe 2'7'-dichlorodihydrofluorescein diacetate (DCFH-DA; Invitrogen; Thermo Fisher Scientific, Inc., Waltham, MA, USA), which is cleaved by cellular esterases to non-fluorescent DCFH and oxidized by intracellular ROS to the fluorescent product dichlorofluorescein. ROS production is proportional to the fluorescence ratio of the treatment vs control group. After the indicated treatments, the cells were incubated with $10 \mu \mathrm{M}$ DCFH-DA for $20 \mathrm{~min}$ at $37^{\circ} \mathrm{C}$ prior to being harvested and analyzed for green and red fluorescence intensity using a flow cytometer (FACSCalibur; BD Biosciences, Franklin Lakes, NJ, USA) at wavelengths of 485 and $528 \mathrm{~nm}$, respectively.

Determination of $\left[\mathrm{Cl}^{-}\right]_{i}$. The measurement of $\left[\mathrm{Cl}^{-}\right]_{i}$ was performed according to the method described in a previous study by our group with minor modifications (8). Briefly, after the indicated treatments, cardiomyocytes were washed twice with $\mathrm{Cl}^{-}$-free solution $(\mathrm{NaCl}$ was replaced by an equimolar amount of D-glucuronic acid, $\mathrm{MgCl}_{2}$ by $\mathrm{MgSO}_{4}$ and $\mathrm{KCl}$ by potassium gluconate), and incubated with $10 \mathrm{mM}$ $N$-(ethoxycarbonylmethyl)-6-methoxyquinolinium (MQAE; Thermo Fisher Scientific, Inc.) in the dark for $20 \mathrm{~min}$ at $37^{\circ} \mathrm{C}$. $\mathrm{Cl}^{-}$-free solution was then used to remove any excess dye. Cells were suspended in $\mathrm{Cl}^{-}$-free solution immediately subjected to flow cytometric analysis (FACSCalibur).

Assessment of $\Delta \psi m$. The fluorescent dye JC-1 was used to assess the mitochondrial membrane potential as described in the study by Tang et al (18). Briefly, after the indicated treatments, cardiomyocytes were incubated with JC-1 (200 $\mu \mathrm{M}$; 
Beijing Solarbio Science \& Technology Co., Ltd.) at $37^{\circ} \mathrm{C}$ for $20 \mathrm{~min}$. Cells were then washed with ice-cold PBS to remove remaining dye. Fluorescence was measured by flow cytometry (FACSCalibur) with excitation/emission wavelengths of $530 / 580 \mathrm{~nm}$ (red) and at 485/530 nm (green). The ratio of red to green fluorescence intensity of cells reflected the $\Delta \psi \mathrm{m}$.

Western blot analysis. Western blotting was performed as described previously (18). The protein concentrations were measured using the DC Protein Assay kit II (cat. no. 500-0112; Bio-Rad Laboratories, Inc.). Equal quantities of protein (30 $\mu \mathrm{l} /$ lane) were then separated by $10 \%$ sodium dodecyl sulfate-polyacrylamide gel electrophoresis and transferred onto polyvinylidene difluoride membranes. After blocking with 5\% non-fat milk in Tris-buffered saline containing $0.2 \%$ Tween 20 (TBST), the blots were probed with rabbit anti-PKC $\varepsilon$ (C-15; 1:500; sc-214), goat anti-p-PKCE (Ser 729; 1:500; sc-12355) and rabbit anti- $\beta$-actin (1:1,000; \#21338) polyclonal antibodies overnight at $4^{\circ} \mathrm{C}$. After washing with TBST, the blots were incubated with horseradish peroxidase-conjugated goat anti-rabbit $(1: 5,000 ; \# 7074)$ and rabbit anti-goat $(1: 5,000$; \#7075) secondary antibodies for $1 \mathrm{~h}$ at room temperature. After washing, the blots were saturated with enhanced chemiluminescence mixture (Pierce Biotechnology, Inc., Rockford, IL, USA) for $1 \mathrm{~min}$, and images of the blot were captured by exposure to pre-flashed X-ray film (Kodak, Rochester, NY, USA). for $300 \mathrm{sec}$. Densitometric scanning was performed using Quantity One software, version 4.62 (Bio-Rad Laboratories, Inc.). Results were expressed as a percentage of the control. The bands were normalized to $\beta$-actin.

Statistical analysis. Data are expressed as the mean \pm standard error of the mean. Statistical analyses were performed using SPSS software, version 11.0 (SPSS, Inc., Chicago, IL, USA). One-way analysis of variance was applied to test the significance of differences between groups, followed by post-hoc testing for individual differences. $\mathrm{P}<0.05$ was considered to indicate a statistically significant difference between values. For each assessment, at least three independent experiments were performed.

\section{Results}

SQS activates PKCE in cardiomyocytes following $s I / R$. Primary cardiomyocytes were incubated with or without $10 \mu \mathrm{M}$ SQS for $24 \mathrm{~h}$, followed by sI/R, and the levels of total and phosphorylated PKCE (Ser 729) were assessed by western blotting. As shown in Fig. 1, the levels of p-PKCe Ser 729 were significantly increased in the SQS pre-treated group $(\mathrm{P}<0.01$ vs. control group; $\mathrm{P}<0.01$ vs. sI/R group), whereas the levels of total $\mathrm{PKC} \varepsilon$ remained unchanged. These results suggested that SQS treatment led to the activation of PKC $\varepsilon$ in cardiomyocytes following sI/R.

$S Q S$ reduces cardiomyocyte death following sI/R via PKCE. The release of $\mathrm{CPK}$ and $\mathrm{LDH}$ into the culture medium was analyzed to evaluate the effects of SQS and PKCE inhibitor EV1-2 on cardiomyocyte death. As shown in Fig. 2, a significant increase in CPK and LDH levels was observed in the sI/R group compared to that in the control group $(\mathrm{P}<0.01)$,

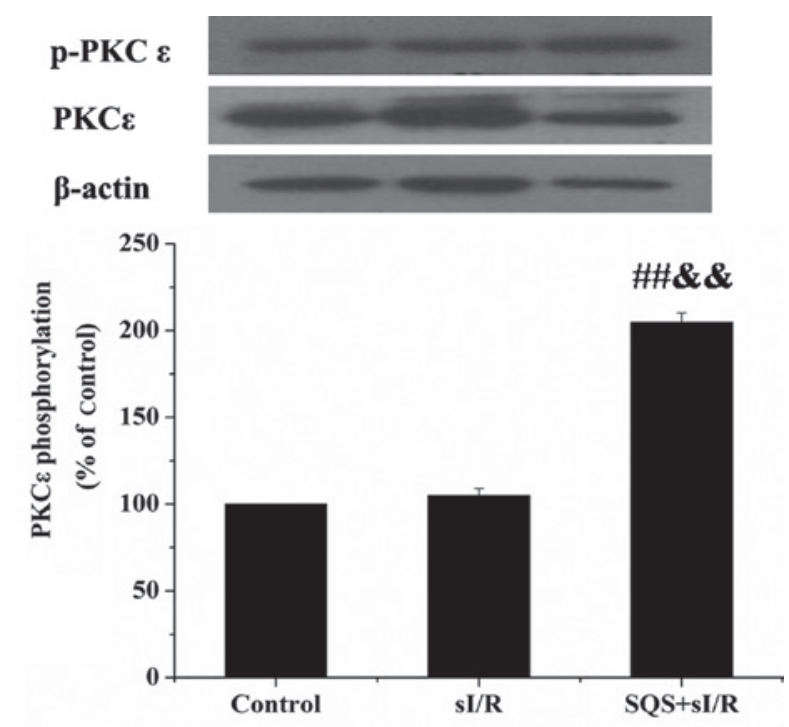

Figure 1. Pre-treatment with SQS (24 h) enhances PKCe phosphorylation at Ser 729 in neonatal rat primary cardiomyocytes subjected to sI/R. A representative western blot is shown and protein levels were quantified by densitometric analysis. Values are expressed as the mean \pm standard error of the mean of at least four independent experiments. ${ }^{\# \#} \mathrm{P}<0.01$ vs. control group; ${ }^{\&} \mathrm{P}<0.01$ vs. sI/R group. sI/R, simulated ischemia/reperfusion; SQS, sasanquasaponin; p-PKC $\varepsilon$, phosphorylated protein kinase $\mathrm{C} \varepsilon$.

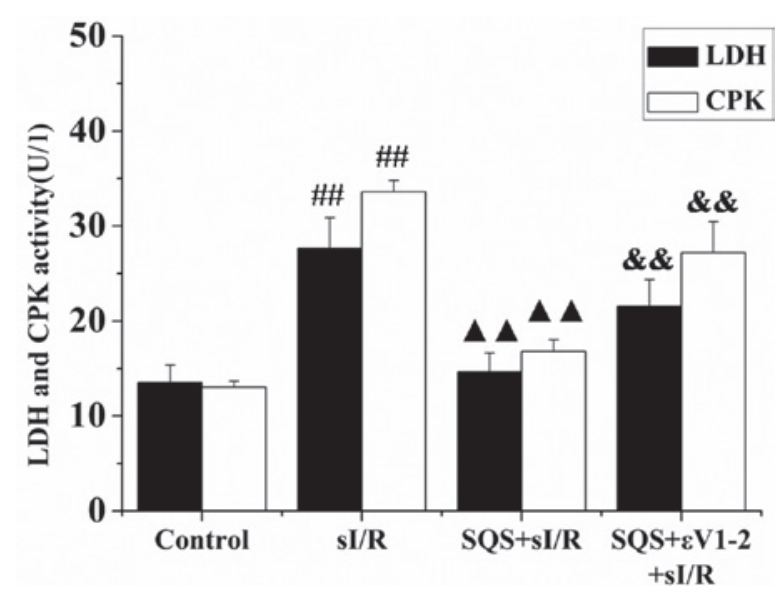

Figure 2. Effects of SQS alone and in combination with protein kinase C epsilon inhibitor $\varepsilon V 1-2$ on LDH and CPK activity in cardiomyocytes subjected to sI/R. Cardiomyocytes were incubated for $24 \mathrm{~h}$ with SQS $(10 \mu \mathrm{M})$ in the absence or presence of $\varepsilon V 1-2(1 \mu \mathrm{M})$ followed by sI/R. Values are expressed as the mean \pm standard error of the mean $(n=6)$. ${ }^{\# \#} \mathrm{P}<0.01$ vs. control group; ${ }^{\wedge} \mathrm{P}<0.01$ vs. sI/R group; \&\& $\mathrm{P}<0.01$ vs. $\mathrm{SQS}+$ sI/R group. $\mathrm{LDH}$, lactate dehydrogenase; CPK, creatine phosphokinase; sI/R, simulated ischemia/reperfusion; SQS, sasanquasaponin.

which was significantly inhibited by pre-treatment with SQS ( $\mathrm{P}<0.01$ vs. sI/R group). Of note, the release of $\mathrm{CPK}$ and $\mathrm{LDH}$ in the group additionally pre-treated with $\varepsilon \mathrm{V} 1-2$ prior to $\mathrm{sI} / \mathrm{R}$ was enhanced when compared with that in the SQS+sI/R group $(\mathrm{P}<0.01)$ (Fig. 2), indicating that SQS may exert its protective effects via PKCE. Furthermore, the results of the MTS assay showed that SQS significantly increased cardiomyocyte viability following $\mathrm{sI} / \mathrm{R}(\mathrm{P}<0.01)$, which was significantly inhibited by co-treatment with $\varepsilon V 1-2$ ( $\mathrm{P}<0.01$ vs. SQS+sI/R group) (Fig. 3). These data suggested that PKC $\varepsilon$ is required for SQS to elicit its cardioprotective effects. 
SQS reduces sI/R-induced increases in $[\mathrm{Cl}]_{i}$ in cardiomyocytes via $P K C \varepsilon$. To investigate whether PKCE is implicated in the inhibitory effects of SQS on the elevation of $\left[\mathrm{Cl}^{-}\right]_{\mathrm{i}}$ induced by $\mathrm{SI} / \mathrm{R}$, cardiomyocytes were treated with PKC $\mathrm{P}$ inhibitor $\varepsilon \mathrm{V} 1-2$ in combination with SQS and $\left[\mathrm{Cl}^{-}\right]_{\mathrm{i}}$ was assessed via MQAE staining and flow cytometric analysis. As shown in Fig. 4, SQS pre-treatment abrogated the increases in $\left[\mathrm{Cl}^{-}\right]_{\mathrm{i}}$ in cardiomyocytes following sI $/ \mathrm{R}$ ( $\mathrm{P}<0.01 \mathrm{vs.} \mathrm{sI/R}$ group), which was inhibited by the selective PKC $\varepsilon$ inhibitor $\varepsilon V 1-2$ ( $\mathrm{P}<0.01$ vs. SQS+sI/R group). These results indicated that activation of PKC $\varepsilon$ is required for SQS to inhibit sI/R-induced elevation of $\left[\mathrm{Cl}^{-}\right]_{\mathrm{i}}$.

SQS attenuates increases of the $\Delta \psi m$ in cardiomyocytes following sI/R via $P K C \varepsilon$. As the decrease of $\Delta \psi \mathrm{m}$ induced by $\mathrm{Cl}^{-}$influx reflects the opening of the mPTP, which results in a ROS burst, the present study assessed the effects of SQS on sI/R-induced changes in $\Delta \psi \mathrm{m}$ in cardiomyocytes as well as the possible involvement of PKCE. As shown in Fig. 5, sI/R decreased the $\Delta \psi \mathrm{m}$ as indicated by a decrease in the ratio of red to green fluorescence intensity ( $\mathrm{P}<0.01$ vs. control group). However, pre-treatment with SQS significantly attenuated the loss of $\Delta \psi \mathrm{m}(\mathrm{P}<0.01 \mathrm{vs}$. sI/R group). As expected, the restorative effect of SQS on the $\Delta \psi \mathrm{m}$ was inhibited by $\varepsilon \mathrm{V} 1-2$ ( $\mathrm{P}<0.01$ vs. $\mathrm{SQS}+\mathrm{sI} / \mathrm{R}$ group), indicating that $\mathrm{PKC} \varepsilon$ is required for SQS-mediated attenuation of $\Delta \psi \mathrm{m}$ loss following sI/R in cardiomyocytes.

SQS inhibits ROS generation in cardiomyocytes undergoing sI/R via $P K C \varepsilon$. Intracellular ROS levels were assessed by measuring cDCF fluorescence intensity. As shown in Fig. 6, sI/R induced marked intracellular ROS production, while pre-treatment with SQS inhibited ROS production induced by sI/R. Co-treatment with $\varepsilon V 1-2$ attenuated the inhibitory effects of SQS on ROS production induced by $s \mathrm{I} / \mathrm{R}$, indicating that $\mathrm{PKC} \varepsilon$ is required for SQS to inhibit sI/R-induced ROS production.

\section{Discussion}

SQS is an active component extracted from the Chinese medicinal herb Camellia oleifera Abel and has gained considerable attention due to its wide range of biological and pharmacological properties (19-21). Previous studies by our group showed that SQS effectively protected against myocardial injury in an isoproterenol-induced rat model of ischemia in vivo and in a hypoxia and reoxygenation model in Langendorff-perfused rat hearts in vitro $(8,22,23)$. Another previous study by our group revealed that SQS exerts its cardioprotective effects by suppressing intracellular $\mathrm{Cl}^{-}$accumulation induced by sI/R (9). The present study investigated the molecular mechanisms underlying SQS-induced effects, focusing on the link between the PKCE signalling pathway and the variations of $\left[\mathrm{Cl}^{-}\right]_{\mathrm{i}}$.

It is well known that $\mathrm{Cl}^{-}$is the primary intracellular anion and that changes in $\left[\mathrm{Cl}^{-}\right]_{\mathrm{i}}$ can affect a variety of basic cellular functions, including ionic conductances, membrane potential, intracellular $\mathrm{pH}$, apoptosis, cell volume and $\mathrm{Ca}^{2+}$ homeostasis $(2,24)$. Studies on ischemic myocardial injury have revealed that $\mathrm{I} / \mathrm{R}$-induced elevation of $\left[\mathrm{Cl}^{-}\right]_{\mathrm{i}}$ is an important pathophysiological factor. Huang et al (4) found that increases in $\left[\mathrm{Cl}^{-}\right]_{\mathrm{i}}$ can lead to the opening of the MPTP, which results in ROS burst and subsequent ROS-dependent cell injury. In line

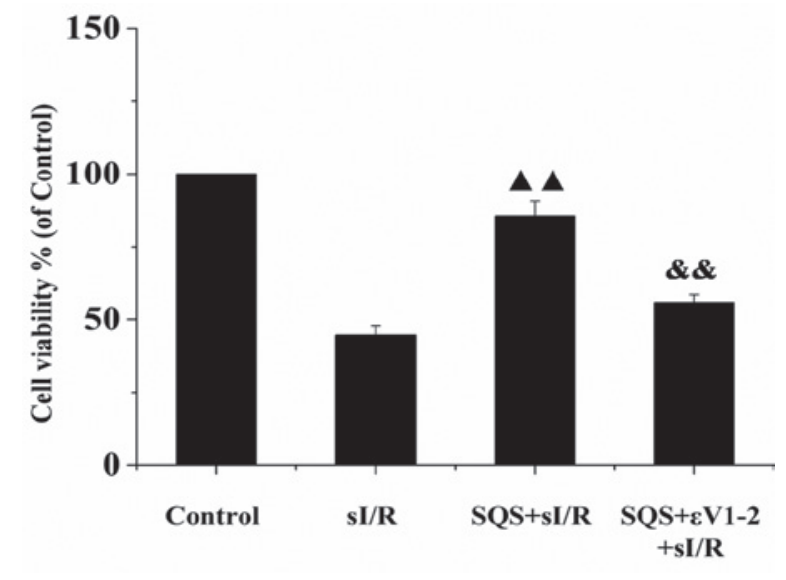

Figure 3. Effects of SQS alone and in combination with protein kinase C epsilon inhibitor $\varepsilon V 1-2$ on the viability of cardiomyocytes subjected to sI/R. Cardiomyocytes were incubated for $24 \mathrm{~h}$ with SQS $(10 \mu \mathrm{M})$ in the absence or presence of $\varepsilon V 1-2(1 \mu \mathrm{M})$, followed by sI/R. Cell viability was measured using the MTS assay. Values are expressed as the mean \pm standard error $(\mathrm{n}=6) .{ }^{\boldsymbol{\Delta}} \mathrm{P}<0.01$ vs. sI/R group; ${ }^{\&} \mathrm{P}<0.01$ vs. $\mathrm{SQS}+\mathrm{sI} / \mathrm{R}$ group. sI/R, simulated ischemia/reperfusion; SQS, sasanquasaponin.

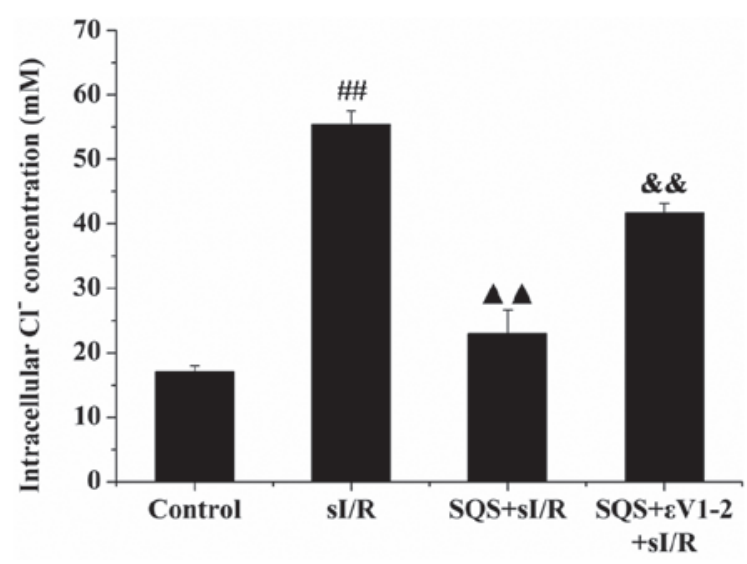

Figure 4. Effects of SQS alone and in combination with protein kinase C inhibitor $\varepsilon V 1-2$ on the intracellular $\mathrm{Cl}^{-}$concentration of cardiomyocytes subjected to $\mathrm{sI} / \mathrm{R}$. Cardiomyocytes were incubated for $24 \mathrm{~h}$ with SQS $(10 \mu \mathrm{M})$ in the absence or presence of $\varepsilon V 1-2(1 \mu \mathrm{M})$ followed by sI/R. The $\mathrm{Cl}^{-}$concentration was determined via the fluorescence of $N$-(ethoxycarbonylmethyl)-6-methoxyquinolinium detected by flow cytometry. Values are expressed as the mean \pm standard error of the mean of four individual experiments. ${ }^{\# \#} \mathrm{P}<0.01$ vs. control group; ${ }^{\boldsymbol{\Delta} \mathbf{P}} \mathrm{P}<0.01$ vs. sI/R group; ${ }^{\&} \mathrm{P}<0.01$ vs. SQS+sI/R group. sI/R, simulated ischemia/reperfusion; SQS, sasanquasaponin.

with this result, the present study found that cardiomyocytes subjected to $\mathrm{SI} / \mathrm{R}$ show a rapid and significant increase in intracellular $\mathrm{Cl}^{-}$levels accompanied by loss of $\Delta \psi \mathrm{m}$, mPTP opening and ROS production. This was also accompanied by cardiomyocyte injury as indicated by a marked increase of LDH and CPK release as well as reduction of cell viability. These results further suggested that dysregulation of intracellular $\mathrm{Cl}^{-}$homeostasis has a significant role in myocardial cell injury induced by ischemia/reperfusion. In addition, SQS was shown to suppress the elevation of $\left[\mathrm{Cl}^{-}\right]_{\mathrm{i}}$ induced by sI/R and induce cardioprotection from sI/R injury in an in vitro cell model. As the underlying molecular mechanisms had remained elusive, the present study assessed the possible role 

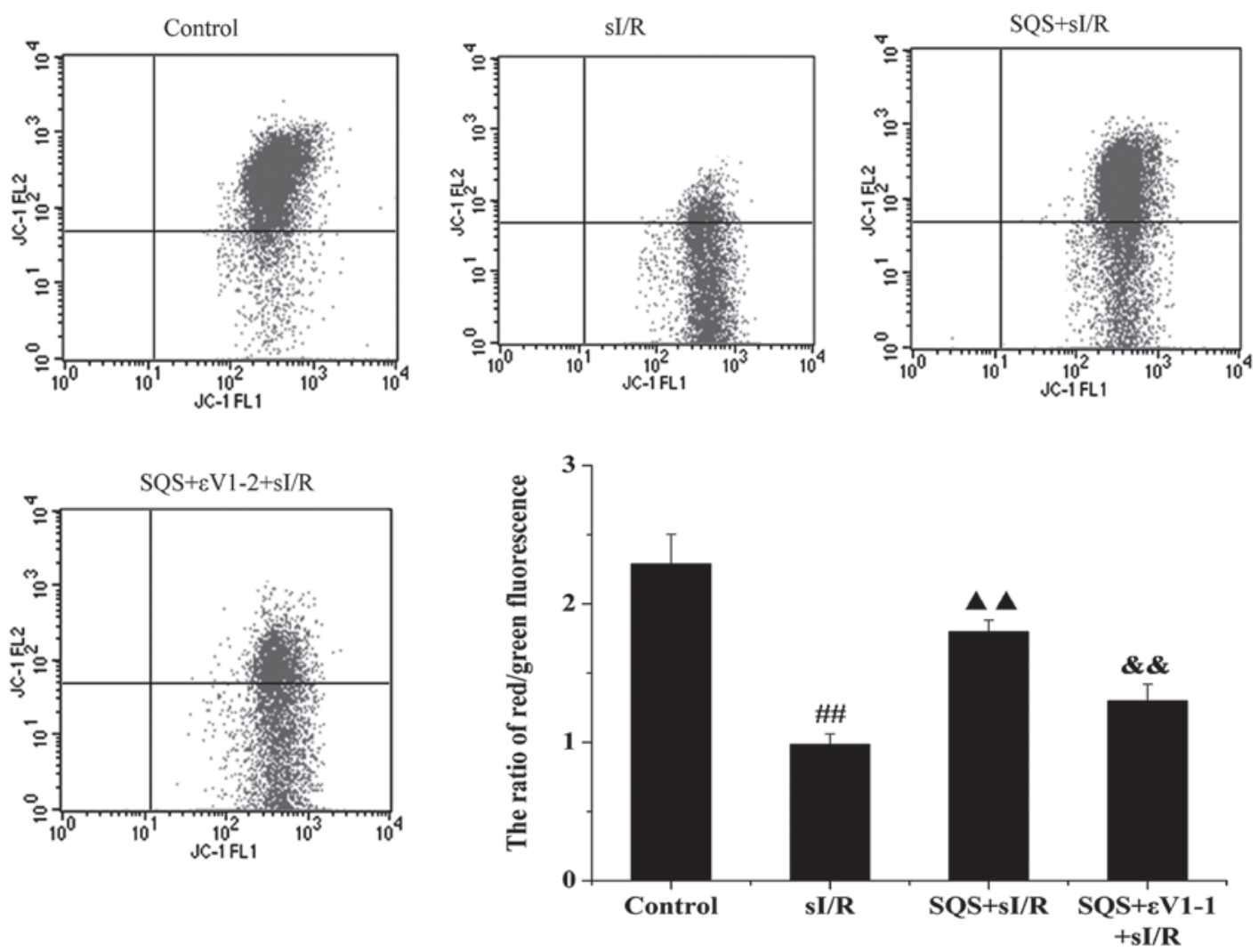

Figure 5. Effects of SQS alone or in combination with protein kinase $\mathrm{C}$ epsilon inhibitor $\varepsilon \mathrm{V} 1-2$ on the mitochondrial membrane potential in cardiomyocytes subjected to sI/R. Cardiomyocytes were incubated for $24 \mathrm{~h}$ with SQS $(10 \mu \mathrm{M})$ in the absence or presence of $\varepsilon V 1-2(1 \mu \mathrm{M})$ followed by sI/R. Representative flow cytometric dot plots are shown. Quantitative evaluation of flow cytometry data provided the red/green fluorescence ratio of the cells to represent the mitochondrial membrane potential. Values are expressed as the mean \pm standard error of the mean of four individual experiments. ${ }^{\# \#<0.01 ~ v s . ~ c o n t r o l ~ g r o u p ; ~}$ ${ }^{\Delta \wedge} \mathrm{P}<0.01$ vs. sI/R group; \&\& $\mathrm{P}<0.01$ vs. SQS+sI/R group. sI/R, simulated ischemia/reperfusion; SQS, sasanquasaponin.
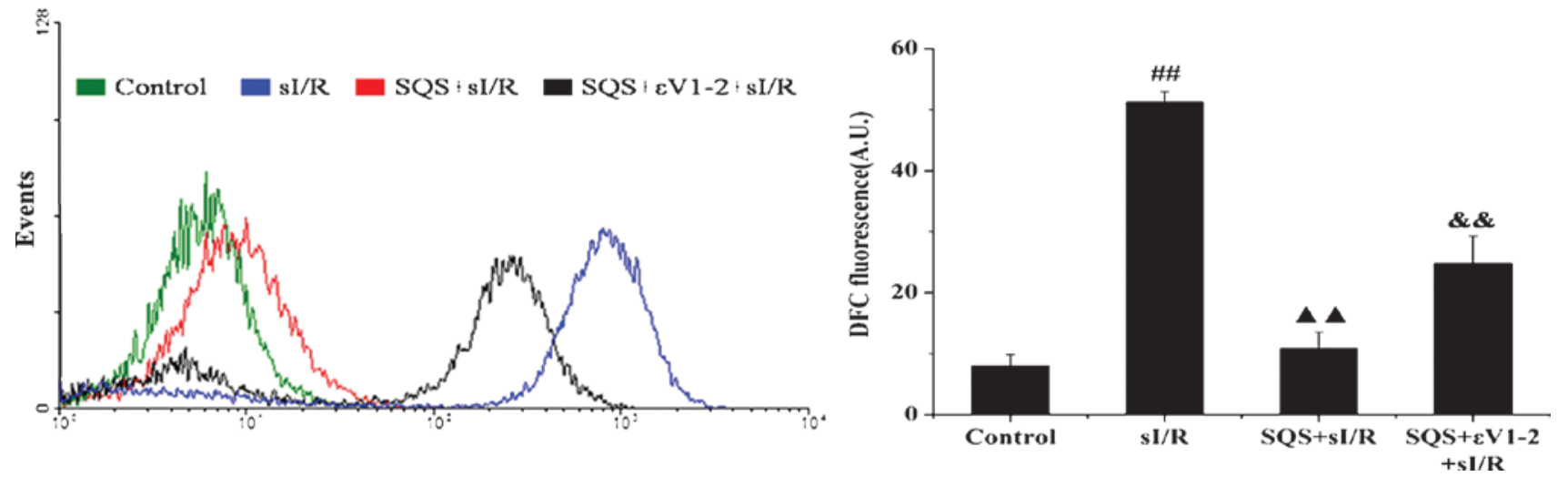

Figure 6. Effects of SQS alone and in combination with protein kinase $\mathrm{C}$ epsilon inhibitor $\varepsilon \mathrm{V} 1-2$ on the generation of ROS in cardiomyocytes subjected to sI/R. Cardiomyocytes were incubated for $24 \mathrm{~h}$ with SQS $(10 \mu \mathrm{M})$ in the absence or presence of $\varepsilon V 1-2(1 \mu \mathrm{M})$ followed by sI/R. The generation of ROS was determined by flow cytometric analysis of the fluorescence of DCF. A representative flow cytometric histogram of DCF fluorescence is shown. The bar graph shows DCF fluorescence representing ROS levels in all groups. Values are expressed as the mean \pm standard error of the mean for four individual experiments. ${ }^{\# \#} \mathrm{P}<0.01$ vs. control group; ${ }^{\mathbf{\Delta}} \mathrm{P}<0.01$ vs. sI/R group; ${ }^{\& \&} \mathrm{P}<0.01$ vs. SQS+sI/R group. DCF, $2^{\prime} 7^{\prime}$-dichlorodihydrofluorescein diacetate; sI/R, simulated ischemia/reperfusion; SQS, sasanquasaponin.

of PKC $\varepsilon$ in the inhibition of sI/R-induced $\left[\mathrm{Cl}^{-}\right]_{\mathrm{i}}$ by SQS in cardiomyocytes.

PKC $\varepsilon$ is a member of a novel group of the PKC family of serine and threonine kinases, which are involved in a wide range of physiological processes, including cell survival under stressful conditions, mitogenesis, transcriptional regulation and metastasis (12). It has been confirmed that PKCE-associated signaling exerts cardioprotective functions (25-27), and that the $\mathrm{PKC} \varepsilon$ pathway is involved in maintaining intracellular chloride homeostasis $(2,16)$. On this basis, the present study hypothesized that activation of the PKC\& pathway may be responsible for the cardioprotective effects of SQS and inhibition of I/R-induced increases in $\left[\mathrm{Cl}^{-}\right]_{\mathrm{i}}$ by SQS. To test this hypothesis, the present study first determined the effects of SQS on the phosphorylation 
of PKC $\varepsilon$ in cardiomyocytes. Of note, pre-treatment with SQS significantly increased the levels of $\mathrm{p}-\mathrm{PKC} \varepsilon$, indicating that $\mathrm{SQS}$ can activate the PKC $\varepsilon$ pathway in cardiomyocytes subjected to $\mathrm{SI} / \mathrm{R}$. To further explore the association between PKCE activation and the cardioprotective effects of SQS, the selective PKCE inhibitor $\varepsilon \mathrm{V} 1-2$ was employed. The results revealed that SQS reduced cardiomyocyte death following sI/R injury, which was inhibited by $\varepsilon V 1-2$. Furthermore, SQS inhibited sI/R-induced elevation of $[\mathrm{Cl}]_{i}$, which was attenuated by $\varepsilon \mathrm{V} 1-2$. These results suggested that activation of PKC $\varepsilon$ is required for SQS to elicit its cardioprotective effects.

Due to the fact that the elevation of $\left[\mathrm{Cl}^{-}\right]_{\mathrm{i}}$ induced by sI/R contributes to loss of $\Delta \psi \mathrm{m}, \mathrm{mPTP}$ opening and ROS production, the present study further detected the effects of $\mathrm{SQS}$ on $\Delta \psi \mathrm{m}$ and ROS production in the absence or presence of $\varepsilon V 1-2$. As expected, it was observed that SQS attenuated the sI/R-induced loss of $\Delta \psi \mathrm{m}$ as well as ROS production in cardiomyocytes, which was inhibited by $\varepsilon \mathrm{V} 1-2$, suggesting that the activation of $\mathrm{PKC} \varepsilon$ is also required for $\mathrm{SQS}$ to attenuate sI/R-induced $\Delta \psi \mathrm{m}$ loss and ROS production.

Although the present study demonstrated that activation of PKCE is required for the inhibitory effects of SQS on the elevation of $\left[\mathrm{Cl}^{-}\right]_{\mathrm{i}}$ following sI/R injury, the detailed molecular interactions deserve further investigation. Anion exchanger 3 (AE3), a member of the solute carrier 4 protein family, mediates the reversible electroneutral exchange of $\mathrm{Cl}^{-}$for $\mathrm{HCO}_{3}{ }^{-}$across the plasma membrane (28). A previous study by our group showed that AE3 is closely linked with the inhibitory effects of SQS on sI/R-induced elevation of $\left[\mathrm{Cl}^{-}\right]_{\mathrm{i}}$ (9). Of note, Alvarez et al (29) showed that AE3 is the PKC-sensitive anion exchange protein of the heart, and that the PKC $\varepsilon$-dependent phosphorylation of serine 67 on AE3 can cause an increase in anion transport. Therefore, it may be speculated that SQS inhibits sI/R-induced elevation of $\left[\mathrm{Cl}^{-}\right]_{\mathrm{i}}$ and induces cardioprotection through activation of the PKCE pathway and consequent PKCE-dependent phosphorylation of serine 67 on AE3. However, this notion requires experimental validation.

In conclusion, the present study was the first to report that activation of PKCE is required for SQS to exert its cardioprotective effects against sI/R injury. It was demonstrated that activation of PKC $\varepsilon$ is crucial for SQS-mediated inhibition of sI/R-induced elevation of $\left[\mathrm{Cl}^{-}\right]_{\mathrm{i}}, \Delta \psi \mathrm{m}$ loss and ROS production. The present study enhanced the current understanding of the molecular mechanisms of the cardioprotective effects of SQS, suggesting that it may be efficient for reducing I/R-induced injury.

\section{Acknowledgements}

The present study was supported by grants from the Natural Scientific Foundation of China (nos. 30660209 and 81260491).

\section{References}

1. Lee YM, Cheng PY, Chen SY, Chung MT and Sheu JR: Wogonin suppresses arrhythmias, inflammatory responses and apoptosis induced by myocardial ischemia/reperfusion in rats. J Cardiovasc Pharmacol 58: 133-142, 2011.

2. Hume JR, Duan D, Collier ML, Yamazaki J and Horowitz B: Anion transport in heart. Physiol Rev 80: 31-81, 2000.
3. Alvarez BV, Kieller DM, Quon AL, Markovich D and Casey JR: Slc26a6: A cardiac chloride-hydroxyl exchanger and predominant chloride-bicarbonate exchanger of the mouse heart. J Physiol 561: 721-734, 2004.

4. Huang QR, Li Q, Chen YH, Li L, Liu LL, Lei SH, Chen HP, Peng WJ and He M: Involvement of anion exchanger-2 in apoptosis of endothelial cells induced by high glucose through an mPTP-ROS-Caspase-3 dependent pathway. Apoptosis 15: 693-704, 2010

5. Ott M, Gogvadze V, Orrenius S and Zhivotovsky B: Mitochondria, oxidative stress and cell death. Apoptosis 12: 913-922, 2007

6. Liu CX and Xiao PG: Recent advances on ginseng research in China. J Ethnopharmacol 36: 27-38, 1992.

7. Attele AS, Wu JA and Yuan CS: Ginseng pharmacology: Multiple constituents and multiple actions. Biochem Pharmacol 58: 1685-1693, 1999.

8. Lai ZF, Shao Z, Chen YZ, He M, Huang Q and Nishi K: Effects of sasanquasaponin on ischemia and reperfusion injury in mouse hearts. J Pharmacol Sci 94: 313-324, 2004.

9. Chen HP, He M, Mei ZJ, Huang QR, Peng W and Huang M: Anion exchanger 3 is required for sasanquasaponin to inhibit ischemia/reperfusion-induced elevation of intracellular Cl-concentration and to elicit cardioprotection. J Cell Biochem 112: 2803-2812, 2011.

10. Ono Y, Fujii T, Ogita K, Kikkawa U, Igarashi K and Nishizuka Y: The structure, expression and properties of additional members of the protein kinase C family. J Biol Chem 263: 6927-6932, 1988.

11. Ohno S, Akita Y, Konno Y, Imajoh S and Suzuki K: A novel phorbol ester receptor/protein kinase, $\mathrm{nPKC}$, distantly related to the protein kinase C family. Cell 53: 731-741, 1988.

12. Akita Y: Protein kinase C-epsilon (PKC-epsilon): Its unique structure and function. J Biochem 132: 847-852, 2002.

13. Liu GS, Cohen MV, Mochly-Rosen D and Downey JM: Protein kinase $\mathrm{C}$-epsilon is responsible for the protection of preconditioning in rabbit cardiomyocytes. J Mol Cell Cardiol 31: 1937-1948, 1999.

14. Ogbi M and Johnson JA: Protein kinase Cepsilon interacts with cytochrome c oxidase subunit IV and enhances cytochrome c oxidase activity in neonatal cardiac myocyte preconditioning. Biochem J 393: 191-199, 2006.

15. Ping PP, Takano H, Zhang J, Tang XL, Qiu Y, Li RC, Banerjee S, Dawn B, Balafonova Z and Bolli R: Isoform-selective activation of protein kinase $\mathrm{c}$ by nitric oxide in the heart of conscious rabbits: A signaling mechanism for both nitric oxide-induced and ischemia-induced preconditioning. Circ Res 84: 587-604, 1999.

16. Budas GR, Churchill EN, Disatnik MH, Sun L and Mochly-Rosen D: Mitochondrial import of PKCepsilon is mediated by HSP90: A role in cardioprotection from ischaemia and reperfusion injury. Cardiovasc Res 88: 83-92, 2010.

17. Watkins SJ, Borthwick GM and Arthur HM: The H9C2 cell line and primary neonatal cardiomyocyte cells show similar hypertrophic responses in vitro. In Vitro Cell Dev Biol Anim 47: 125-131, 2011.

18. Tang L, Peng Y, Xu T, Yi X, Liu Y, Luo Y, Yin D and He M: The effects of quercetin protect cardiomyocytes from A/R injury is related to its capability to increasing expression and activity of PKCe protein. Mol Cell Biochem 382: 145-152, 2013.

19. Chen HP, He M, Huang QR, Liu D and Huang M: Sasanquasaponin protects rat cardiomyocytes against oxidative stress induced by anoxia-reoxygenation injury. Eur $\mathrm{J}$ Pharmacol 575: 21-27, 2007.

20. Akagi M, Fukuishi N, Kan T, Sagesaka YM and Akagi R: Anti-allergic effect of tea-leaf saponin (TLS) from tea leaves (Camellia sinensis var. sinensis). Biol Pharm Bull 20: 565-567, 1997.

21. Sur P, Chaudhuri T, Vedasiromoni JR, Gomes A and Ganguly DK: Antiinflammatory and antioxidant property of saponins of tea [Camellia sinensis (L) O. Kuntze] root extract. Phytother Res 15: 174-176, 2001.

22. Liu D, He H, Li GL, Chen J, Yin D, Liao ZP, Tang L, Huang QR, Lai ZF and He M: Mechanisms of chloride in cardiomyocyte anoxia-reoxygenation injury: The involvement of oxidative stress and NF-kappaB activation. Mol Cell Biochem 355: 201-209, 2011.

23. Liao Z, Yin D, Wang W, Zeng G, Liu D, Chen H, Huang Q and $\mathrm{He} \mathrm{M}$ : Cardioprotective effect of sasanquasaponin preconditioning via bradykinin-NO pathway in isolated rat heart. Phytother Res 23: 1146-1153, 2009. 
24. Hiraoka M, Kawano S, Hirano Y and Furukawa T: Role of cardiac chloride currents in changes in action potential characteristics and arrhythmias. Cardiovasc Res 40: 23-33, 1998.

25. Ping P, Song C, Zhang J, Guo Y, Cao X, Li RC, Wu W, Vondriska TM, Pass JM, Tang XL, et al: Formation of protein kinase C (epsilon)-Lck signaling modules confers cardioprotection. J Clin Invest 109: 499-507, 2002.

26. Schwanke U, Konietzka I, Duschin A, Li X, Schulz R and Heusch G: No ischemic preconditioning in heterozygous connexin43-deficient mice. Am J Physiol Heart Circ Physiol 283: H1740-H1742, 2002.
27. Schulz R, Cohen MV, Behrends M, Downey JM and Heusch G: Signal transduction of ischemic preconditioning. Cardiovasc Res 52: 181-198, 2001

28. Alper SL, Darman RB, Chernova MN and Dahl NK: The AE gene family of $\mathrm{Cl} / \mathrm{HCO}_{3}$ exchangers. J Nephrol 15 (Suppl 5): S41-S53, 2002

29. Alvarez BV, Fujinaga J and Casey JR: Molecular basis for angiotensin II-induced increase of chloride/bicarbonate exchange in the myocardium. Circ Res 89: 1246-1253, 2001. 